\title{
FDTD Simulation of a Mobile Phone Operating Near Metals
}

\author{
Nuttaka Homsup and Terapass Jariyanorawiss \\ Faculty of Engineering \\ Kasetsart University \\ Thailand
}

\begin{abstract}
This paper presents Finite Difference Time Domain (FDTD) simulation results of operating mobile phone near metal wall sheet and near a one metal cell. Results show that placing a one metal cell closed to a mobile phone is more harmful to human health than a metal wall sheet. The one metal cell is the Yee's cell that has a metal characteristic, high conductivity and low permittivity. In general, the mobile phone was modeled by a dipole antenna so the one metal cell's characteristic can be chosen as the dipole's characteristic. This simulation uses Finite Difference Time Domain (FDTD) scheme. It's domain is divided into two parts: the physical domain and the artificial domain. The physical domain consists of a dipole antenna located at $1 \mathrm{~cm}$ from a human head model and a one metal cell varied distance $(\Delta \mathrm{I})$ from the dipole. In addition, the dipole antenna operated at $900 \mathrm{MHz}$ and $1800 \mathrm{MHz}$ was used in the simulation. The artificial domain is a Perfectly Matched Layer (PML). The PML acts as an electromagnetic field absorbing layer and was backed by a Perfect Electric Conductor (PEC). The Specific Absorption Rate (SAR) was computed and averaged on a tissue mass of one gram and ten grams, SAR 1-g and SAR 10-g, respectively. Also, the average power (Pavg) absorbed in various human tissues is computed with a distance between the dipole antenna and a one metal cell as a varying parameter $(\Delta \mathrm{l})$. Simulation results from a one metal cell will be compared to referenced values. There are three reference SAR values: the standard SAR 1-g (FCC, Federal Communications Commission), the simulation in an open area and the simulation with the metal wall. In this case, results from the simulation show that the computed SAR 1-g and SAR 10-g values are not exceed the limitation values established by various standard institutes (1.6 Watt $/ \mathrm{kg})$, however, for $\Delta \mathrm{l}=0-5 \mathrm{~cm}$, both of the SAR and the average power absorb are higher than the simulation with the metal wall and the simulation in an open area.
\end{abstract}

Keywords-FDTD, PML, metal wall, one metal cell

\section{INTRODUCTION}

In recent years mobile phones or smart phones have gained popularity because of its versatility: internet capabilities, navigation and cameras. All of the smart phones integrate with built in antenna and cases: metallic case, plastic case and plastic case with metallic decorations. Sometime, the metallic case and the plastic case with metallic decorations can be a reflector of the built in antenna by accident. This paper assumes the metallic case is something like an infinite metal wall [1] located at $0-1 \mathrm{~cm}$ from the antenna. This implies that the plastic case with metallic decorations is something like a one metal cell located at $0-1 \mathrm{~cm}$ from the antenna. In addition, the one metal cell is the one Yee's cell that has a metal characteristic, high conductivity and low permittivity. The mobile phone is represented as the dipole antenna corresponding to the operating frequencies: $900 \mathrm{MHz}$ and $1800 \mathrm{MHz}$

The results of the simulation of a mobile phone operating near a metal wall show that the computed SAR 1-g and SAR 10 -g values are not exceed the limitation values (1.6 Watt $/ \mathrm{kg}$ ) establish by Federal Communications Commission (FCC). Especially, the metal wall located at $0-5 \mathrm{~cm}$ from the dipole gives both SAR values lower than the standard. Then using the mobile phone covered with metallic case is safer than using the mobile phone covered with plastic case (the open area). As describe above, this research compares SAR 1-g, SAR 10-g and average power absorbed in human head of simulation the mobile phone operating near a one metal cell and a metal wall model.

\section{THE REFERENCE SAR VALUES}

There are three reference SAR values: the standard SAR 1$\mathrm{g}=1.6 \mathrm{Watt} / \mathrm{kg}$ (FCC, Federal Communications Commission), the simulation in an open area (the plastic case) and the simulation with the metal wall (the metallic case). The open area model and the metal wall model are shown in Fig. 1 and Fig. 2, respectively.

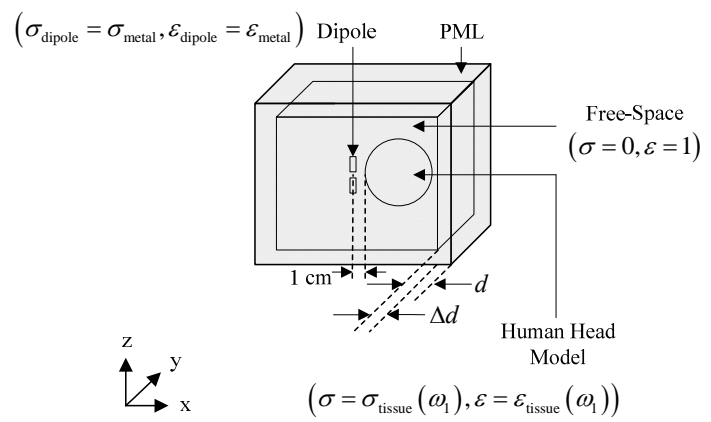

FIGURE I. THE SIMULATION IN AN OPEN AREA 


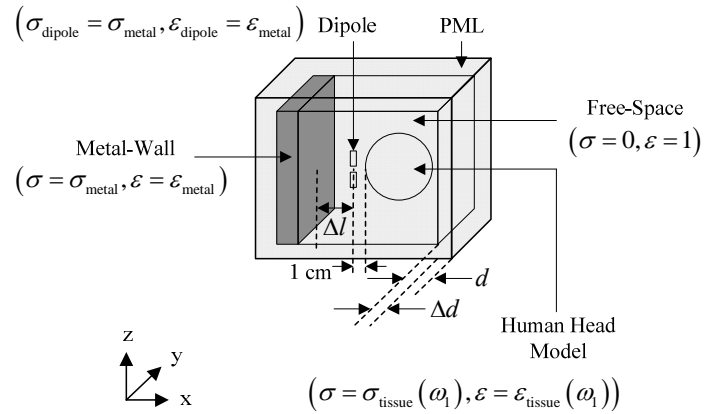

FIGURE II. THE SIMULATION WITH THE METAL WALL

\section{The Simulation MOdeL}

In general, mathematical theory and various implementations of FDTD were presented in [1]-[11]. Also, for comparison, results of FDTD simulation with the metal wall model were presented in [1]. The one metal cell model is shown in Fig. 3. The one metal cell is located next to the dipole and varied distance $(\Delta l)$ between the dipole and the one metal cell. For $\Delta l=0-10 \mathrm{~cm}$, this paper computes the SAR 1-g, the SAR 10-g and the average power absorbed in human head.

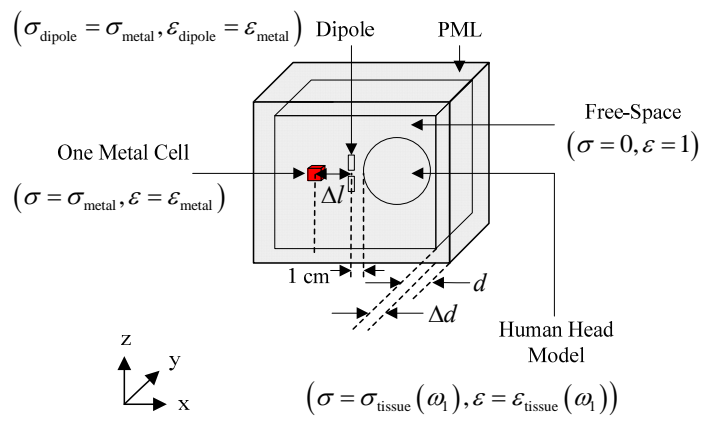

FIGURE III. THE SIMULATION WITH THE ONE METAL CELL.

\section{The Simulation Results}

Fig. 4-5 shows top view of the tangential electric field in the simulated physical domain of the one metal cell.

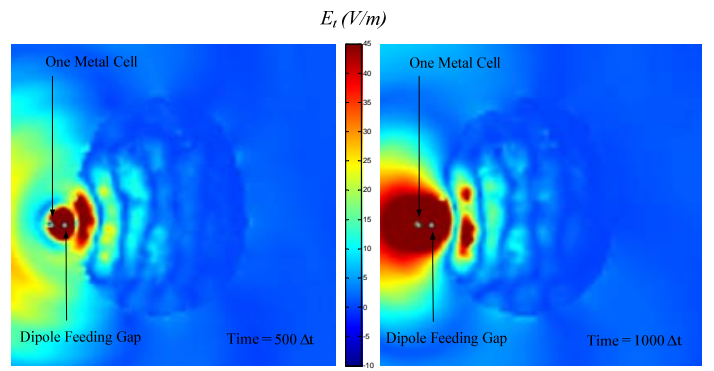

FIGURE IV. TOP VIEW OF ET IN THE SIMULATED PHYSICAL DOMAIN AT $900 \mathrm{MHZ}$

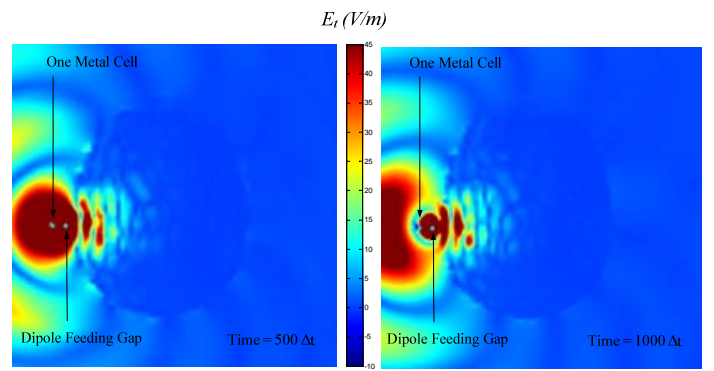

FIGURE V. TOP VIEW OF ET IN THE SIMULATED PHYSICAL DOMAIN AT $1800 \mathrm{MHZ}$

Spatial-average SAR 1-g, SAR 10-g and average power absorbed are shown as the following figures

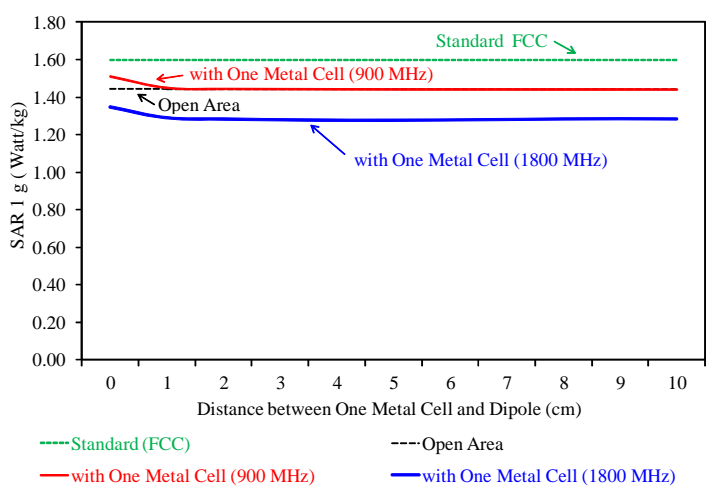

FIGURE VI. SPATIAL-AVERAGE SAR 1-G FROM THE ONE METAL CELL SIMULATION

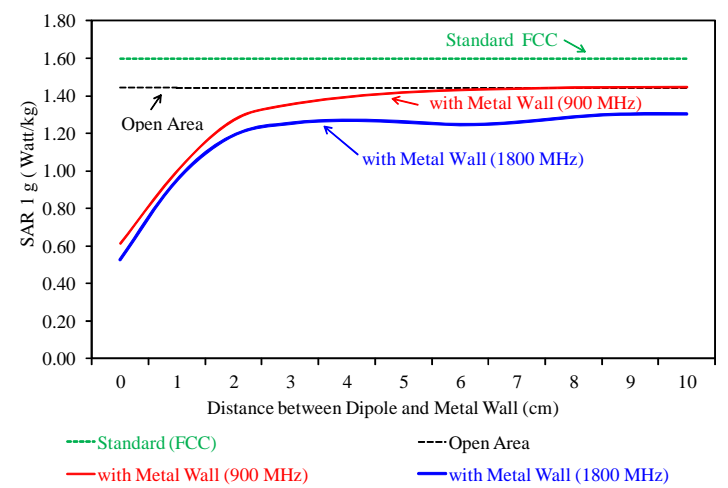

FIGURE VII.

SPATIAL-AVERAGE SAR 1-G FROM THE METAL WALL SIMULATION 


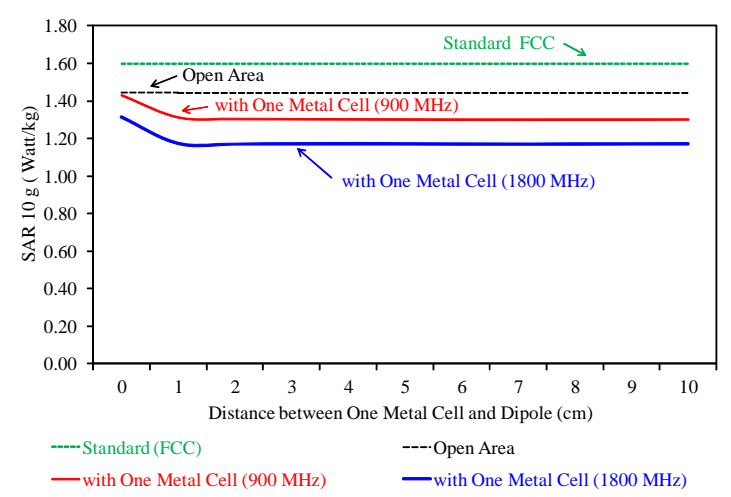

FIGURE VIII. SPATIAL-AVERAGE SAR 10-G FROM THE ONE METAL CELL SIMULATION.

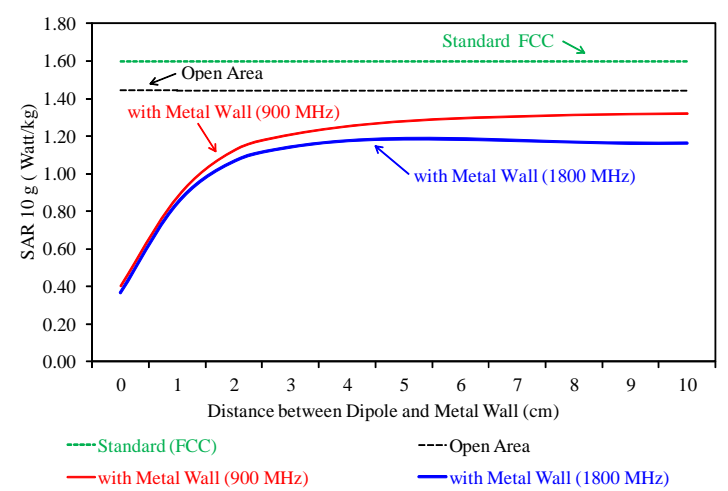

FIGURE IX. SPATIAL-AVERAGE SAR 10-G FROM THE METAL WALL SIMULATION.

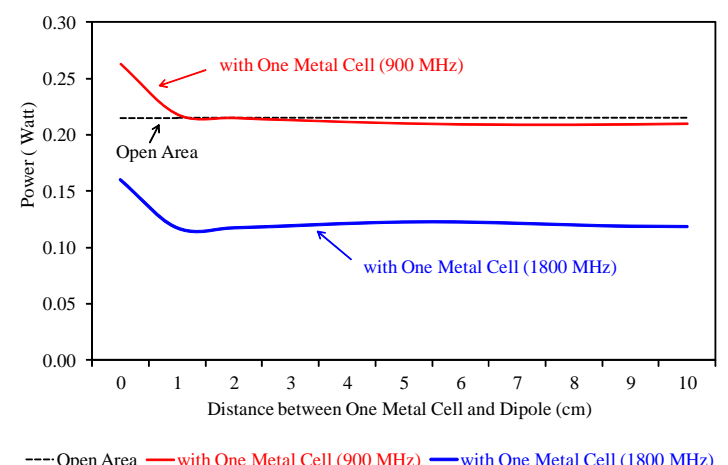

FIGURE X. THE AVERAGE POWER ABSORBED IN HUMAN HEAD FROM THE ONE METAL CELL SIMULATION.

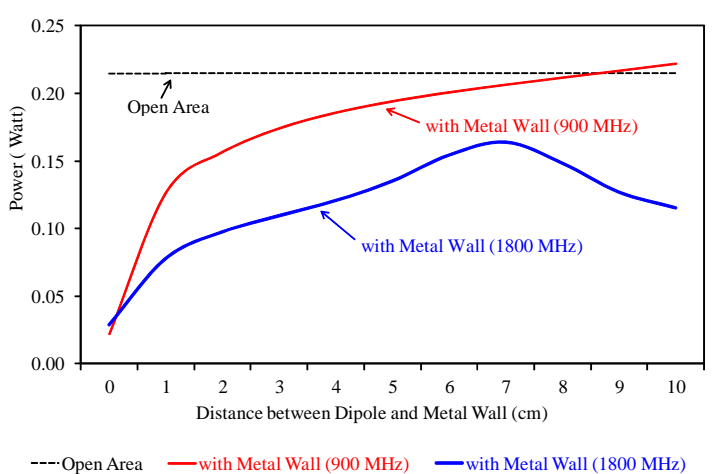

FIGURE XI. THE AVERAGE POWER ABSORBED IN HUMAN HEAD FROM THE METAL WALL SIMULATION.

\section{CONCLUSION}

The FDTD scheme have been applied to the one metal cell and a metal wall simulation model .Operated frequencies are $900 \mathrm{MHz}$ and $1800 \mathrm{MHz}$. Results of the simulation of a mobile phone operating near a metal wall and a one metal cell show that SAR 1-g and SAR 10-g do not exceed the ANSI/IEEE standard. Surprisingly, both SARs and the average power absorbed in human head are higher than the metal wall simulation model. In brief, placing a one metal cell closed to a mobile phone is more harmful to human health than a metal wall sheet

\section{REFERENCES}

[1] N. Homsup, T. Jariyanorawiss, and W. Homsup, "FDTD Simulation of a Mobile Phone Operating near a Metal Wall”, Journal of Computer, Academy Publisher, pp. 168-175, February 2009.

[2] K.S. Yee, "Numerical Solution of Initial Boundary Value Problems Involving Maxwell's Equations in Isotropic Media,” IEEE Transactions on Antennas and Propagation, Vol.14, pp.302-307, 1966.

[3] N.K. Kouveliotis, P.T. Trakadas and C.N. Capsalis, "Investigation of A Dipole Antenna Performance and SAR Distribution Induced in A Human Head Model,” National Technical University of Athens, Athens, Greece.

[4] N. Homsup, T. Jariyanorawiss, and W. Homsup, "Truncation of the Head Model in Cellular Phone Simulations Using a Simple PML Formulation," Proceedings of the International Conference on International Symposium on Communications and Information Technologies 2004 (ISCIT 2004), pp. 793-796, Sapporo, Japan, October 26-29, 2004.

[5] J.P. Berenger, "Three-Dimensional Perfectly Matched Layer for the Absorption of Electromagnetic Wave,” Journal of IEEE Transactions on Computational Physics, Vol.127, pp.363-379, 1996.

[6] L. Ling, L. Ronglin, X. Suming and N. Guangzheng, “A New Generalized Perfectly Matched Layer for Terminating 3-D Lossy Media,” IEEE Transactions on Magnetics, Vol. 38, No. 2, pp. 713-716, 2002.

[7] K.W.L. Fabian, Modeling of Electromagnetic Wave Propagation in Printed Circuit Board and Related Structures. Ph.D. Thesis, Multimedia University, Malaysia, 2003.

[8] T. Jariyanorawiss and N. Homsup, "Implementation of FDTD Scheme Using PML for Truncation of the Head Model in Cellular Phone Simulations," Proceedings of the International Conference on International Symposium on Communications and Information Technologies 2005 (ISCIT 2004), pp. 623-626, Beijing, China, October 12-14, 2005. 
[9] A. Taflove and S. C. Hageness, Computational Electrodynamics: The Finite-Difference Time-Domain Method. Norwood, MA: Artech, 2000.

[10] K.S. Kunz and R. J. Luebbers, The Finite-Difference Time-Domain Method in Electromagnetics. Boca Raton, FL: CRC, 1993.

[11] S. Watanabe and T. Masao, “An improved FDTD Model for the Feeding Gap of a Thin-Wire Antenna,” IEEE Microwave and Guided Wave Letters. Vol. 8, pp. 152-154, 1998. 